\title{
De la lectura menor a la poética traficante. Primeras anotaciones en torno a la poesía de Tomás Harris y Nicolás Miquea
}

\section{From the minor Reading to the Poetic Trafficker. First Notes about the Poetry of Tomás Harris and Nicolás Miquea}

\section{Ricardo Espinaza Solar}

Facultad de Ciencias Humanas, Universidad Arturo Prat. Iquique, Chile.

respinaz@unap.cl

\section{Resumen}

A partir de la noción de "literatura menor" propuesta por Gilles Deleuze, el artículo comprende una aproximación general a las escrituras de los poetas chilenos Tomás Harris y Nicolás Miquea, para plantear la posibilidad de una "lectura menor" en tanto ejercicio de reflexión para la escritura crítica de ambos autores. Así, desde un amplio enfoque teórico, el artículo también explora la identidad de lo poético en tanto acontecimiento de salud, otredad y estética relacional para la formulación conceptual de una "poética traficante".

Palabras clave: lectura menor, acontecimiento de salud, estética relacional, poética traficante, Tomás Harris, Nicolás Miquea.

\section{Abstract}

From the notion of "minor literature" proposed by Gilles Deleuze, the article comprises a general approach to the writings of the Chilean poets Tomás Harris and Nicolás Miquea, to raise the possibility of a "minor reading", as an exercise of reflection on both authors. From a broad theoretical approach, the article also explores the identity of poetry as health event, otherness, and relational aesthetics for the conceptual development of a "poetic trafficker".

Keywords: Minor Reading, Health Event, Relational Aesthetics, Poetic Trafficker, Tomás Harris, Nicolás Miquea. 


\section{Posibilidades y acontecimientos para una lectura menor}

Ante la posibilidad de lectura de las obras poéticas de los escritores chilenos Tomás Harris (La Serena, 1956) y Nicolás Miquea (Llay-Llay, 1951), asoma un intercambio y circulación de sentidos varios que deviene en acontecimiento. Una realidad materializada en la palabra e inscrita en el verso. Un acontecimiento de la escritura que a la vez se transfigura en una advertencia al lector como algo que siempre vendrá. Un nuevo acontecimiento por venir.

Así, ante la relación que ocurre entre escritura y lector igualmente adviene una especie de desplazamiento. Acontecimiento y desplazamiento que sobreviene en trayecto o tránsito. Un tráfico o transporte cuyo sentido y propósito va mucho más allá de la movilidad retórica de las metáforas, las imágenes y otras figuras afluentes, porque la literatura es aquella escritura que en pos de una "salud" trama desplazamientos. Recorridos por el lenguaje que para Tomás Harris consisten en "el fragmento la parte el par / sin cara" (Cipango 41), mientras que para Nicolás Miquea sucede que "después de todo vino a resultar / que nadie sabía hacia dónde íbamos" (Fermosa 35). Así entonces, escritura de fragmentos e incertidumbres en constante movimiento que para estos poetas se traducen en una posibilidad de ser y no ser, de estar y no estar, de acontecer y desplazarse poéticamente a la vez.

Siguiendo el pensamiento de Gilles Deleuze, podemos recordar que para el filósofo francés escribir es siempre una posibilidad de "devenir". Un devenir siempre inacabado y siempre en curso que va desbordando cualquier materia vivible o vivida, $y$ es por ello que no hay líneas rectas ni en el lenguaje ni en las cosas; la sintaxis poética es el resultado de un conjunto de senderos que se añaden y bifurcan. Un laberinto de caminos indirectos creados en cada ocasión de escritura y lectura para poner de manifiesto la vida en las cosas, en tanto zonas de vecindad e indeterminación (Deleuze 11), como "zonas de peligro ininteligibles" (Harris, Cipango 29). Espacios de la incertidumbre y del "entre" que son los agujeros del mundo y, a su vez, los agujeros de la realidad, "agujeros de gritos poblando el silencio" (46). Lo indiscernible del lenguaje y la salud de la vida "que me dicen agujereada del presente infinito del poeta [...] y apenas si alcanzo a girar la cabeza agujereada de la incertidumbre" (Miquea, Libro de Atanasio 195). Zonas, espacios y agujeros por los que generalmente no se llega nunca a ser sino a estar siempre en vías de ser algo distinto.

Escribir, dice Deleuze, "es un asunto de devenir, siempre inacabado, siempre en curso [...] y devenir no es alcanzar una forma (identificación, imitación, Mimesis), sino encontrar la zona de vecindad, de indiscernibilidad o de indiferenciación tal que ya no quepa distinguirse" (12). Continuando con esta idea, tiendo a creer que en la escritura poética de Harris y Miquea acontecen ciertos agujeros indiscernibles de expresión por los que el sujeto poético deviene como "por un gran agujero entre el cielo y la tierra" (Miquea, Que nos queremos 71), "por donde las estrellas eran orificios en el cielo [...] huecos por donde se transparentaba el baldío” (Harris, Cipango 50). 
Ciertamente, sabemos del ejemplar agujero indiscernible de expresión rimbaudiana que, producido por el desorden de los sentidos, declara "yo es otro". Desde entonces, además, la poesía ya no "es" sino que "está siendo" un otro para huir del ser. Una otredad que se fuga hacia lo informe o lo inacabado; o bien, que se desplaza y acontece en posibilidades de indeterminación, en agujeros de expresiones de alteridad, en "oscuros vacíos hacia el final del pensamiento" (Cipango 76), "digo escribo y se / vuelca el vacío más allá del poema” (Miquea, Fermosa 49).

Sobre esto último, y a propósito de la poesía latinoamericana, el crítico Mario Rodríguez Fernández ha declarado que con el "devenir" la palabra poética permanece en el círculo de atracción del verbo estar y huye del círculo del verbo ser (24), por lo que la palabra poética es ya un acontecimiento de la otredad. Una intensidad delirante que deshace la identidad: "en el delirio que / acompaña el amor, en el delirio impune en que / terminábamos todos, comenzamos a imaginarnos cosas: yo, en la penumbra, te abrazaba el cuerpo pensando / que te abrazaba el cuerpo en la claridad" (Harris, Cipango 55); o bien: "Yo soy todos los nombres de mis fábulas. Yo soy nadie y con ello miento mi existencia y vivo. Yo soy ella, la poesía. Ella somos nosotros, el acontecer" (Miquea, Que nos queremos 13).

Así también, para el autor de Crítica y clínica, el devenir del sujeto poético ocurre por medio de un conjunto de expresiones delirantes que no son manifestaciones enfermizas sino saludables. El delirio puede ser un síntoma patológico cuando es nominado por las fuerzas del orden: el delirio es una enfermedad, la enfermedad por antonomasia, cuando erige una raza supuestamente pura y dominante. Pero, a la vez, el delirio es un modelo de salud cuando invoca a una raza bastarda y oprimida que se agita sin cesar bajo las dominaciones, que resiste a todo lo que la aplasta o la aprisiona y se perfila en la literatura como proceso o creación procesual (16). De manera similar, Félix Guattari, en "El nuevo paradigma estético", ensayo incluido en el libro Caosmosis, señala que las prácticas artísticas y literarias se encuentran animadas por un "creacionismo mutante", siempre por reinventar, siempre en trance de perderse, como mecanismo para la producción de nuevos infinitos a partir de la inmersión en la finitud sensible. Infinitos cargados de virtualidad potencial y actualizables en cada situación para desmarcarse de los universales inventariados por el arte (142). De modo que toda escritura literaria contiene efectivamente la rimbaudiana cualidad de "estar siendo otra" en un proceso infinito. Las escrituras de Harris y Miquea son, por su parte, un intento por hacer manifiesto, en su delirio, la producción de un decir revolucionario en tanto posibilidad de vida. Un agujero como acontecimiento de vitalidad o una identidad vivificante de la poesía: "Digo vida y no queda, / se vuelve violenta / calcinando la página" (Miquea, Fermosa 49). El acontecimiento de una nueva salud o el devenir de una salud otra como un proceso de medicina ${ }^{1}$ que posibilita un des-

1 Según Gilles Lipovetsky: "La medicina también presenta una evolución paralela: acupuntura, visualización del interior del cuerpo, tratamiento natural por hierbas, biofeedback, homeopatía. Las terapias 'suaves' ganan terreno 
plazamiento desde la finitud del ser hacia la indiscernibilidad infinita del estar nada más que en las palabras del trayecto hacia un otro. Zona heterotópica que, como bien señalaba Michel Foucault, posiblemente no sea sino la indeterminación del ser de las palabras. El ser del lenguaje habitando en el blanco de la página (63), "el puro blanco / el blanco sin intersticios para detenerse a respirar” (Harris, Cipango 42).

Por ello Rodríguez Fernández, lector de Deleuze, también afirma que "el delirio del poeta es una empresa de salud" (36). Pero no se trata de una gran salud, sino de una salud otra, "una irresistible salud pequeñita producto de lo que [el poeta] ha visto y oído de las cosas demasiado grandes para él, demasiado fuertes para él, irrespirables, cuya sucesión le agota, y que le otorgan no obstante unos devenires que una salud de hierro y dominante haría imposible" (Deleuze 14). Sin embargo, esta nueva salud como acontecimiento de la otredad, que ocurre desde la subjetividad poética para manifestarse en la identidad del lenguaje es, a la vez, un acontecimiento en los lindes del lenguaje. Acontecimiento en donde el poeta deviene "médico de sí mismo" a la vez que se rebela ante el poder de decir Yo: "Yo soy el autor, yo soy / el poeta, la ficción, / la biografía. Escribo [...] Yo soy todos los nombres / de mis informes. Yo soy / Nadie / y con ello miento / mi existencia / y vivo. Yo soy ella, la poesía. Ella somos nosotros, el acontecer" (Miquea, Libro de Atanasio 78). Porque bien ha dicho Deleuze que la salud como literatura, como poesía y escritura, consiste en inventar un "pueblo que falta" (15), una otredad que habita tan solo en el lenguaje de esas fábulas del pueblo ausente. "Estábamos en nuestro / propio pueblo no estábamos en nuestro propio pueblo. Los pueblos eran pueblos fantasmas" (Harris, Cipango 56). "En la casa había una sombra / que debía existir / porque había algo que no debía estar / había oxígenos y eso era una sombra / porque había algo en la forma / porque había algo que no debía estar / que debía estar nombrándose / y eso era una fábula" (Miquea, Libro de Atanasio 53). De este modo, es posible señalar que aquello que deviene y que delira, que hace agujeros y crea una salud nueva en el ser mismo del lenguaje y los sujetos, no es más que la propia palabra poética en tanto posibilidad y acontecimiento de la otredad. Desplazamiento y tráfico. Un devenir-otro de la lengua en la lengua o bien aquello a lo que se refiere Deleuze cuando al citar a Marcel Proust alude a una lengua extranjera o bien cuando cita a Franz Kafka para referirse a una lengua menor. Una alternativa del decir. Una posible intensidad de la palabra por un otro nacimiento (im)posible en la imaginación: "A la palabra imposibilidad, nos reconocíamos / en los cuerpos desmembrados por la imaginación” (Harris, Cipango 59). El otro nacer de la vida:

Vidas ajenas

me habitan

Me encuentro a cada instante a boca de jarro

enfatizando la subjetivación de la enfermedad, la asunción 'holística' de la salud por el propio sujeto, la exploración mental del cuerpo, en ruptura con el dirigismo hospitalario; el enfermo no debe sufrir su estado de manera pasiva, él es el responsable de su salud, de su sistema de defensa gracias a las potencialidades de la autonomía psíquica" (21). 


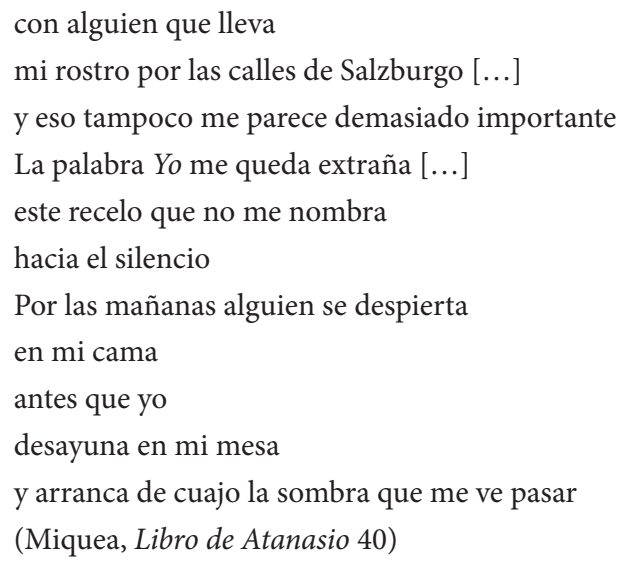

Ahora bien, Deleuze cita a Proust para señalar una especie de devenir-otro de la lengua en la literatura. Un devenir de otredad equivalente a "una línea mágica que escapa del sistema dominante" (16). Tales líneas mágicas constituyen una especie de "efectos de sintaxis" en donde el escritor no solo destruye su lengua materna sino que a la vez también crea una lengua-otra, como si se tratara de un agujero al interior del sistema lingüístico dominante para declarar el paso de la vida al lenguaje, un paso que incluso a veces va "más allá de la sintaxis" (17). Una salud en que solo habita el agujero y el tráfico: la intensidad de un lenguaje desterritorializado "al centro mismo de un viaje sin regreso" (Harris, Cipango 136) o "un retorno sin voz a la escritura" (Miquea, Que nos queremos 15). Por ello también el teórico francés hablará de una "literatura menor", para afirmar que solo mediante el lenguaje el escritor construye algún tipo de procedimiento de otredad ${ }^{2}$. Por tal razón, lo "menor" no responde a un calificativo para ciertas literaturas, sino que atañe a las condiciones revolucionarias de cualquier producción literaria que afecta el seno de lo que es llamado "literatura mayor", en tanto literatura establecida como lengua estética y políticamente dominante para la colectividad. En consecuencia, es al interior del espacio literario de la otredad donde aparece una colectividad invisible, menor, anulada y olvidada. Aquello bien puede apreciarse en las siguientes heterotopías poéticas de los muertos olvidados, presentes en el libro Que nos queremos tanto de Nicolás Miquea:

DE LOS MUERTOS IMAGINARIOS DE CONCEPCIÓN,

ESPLÉNDIDOS OBJETOS REPITIÉNDOSE EN LAS

2 Ejemplificando con la obra de Franz Kafka, Deleuze señala que para el logro de la expresión en tanto procedimiento de otredad, lo específicamente "menor" no se define como la literatura de un idioma menor sino como la literatura que una minoría realiza dentro de una lengua mayor. Literatura menor que, en definitiva, es concebida específicamente por el uso del lenguaje sobre la base del fuerte coeficiente de desterritorialización que afecta al idioma y también por una enunciación política que adquiere valor colectivo. Por ello también el crítico Edson Faúndez V., leyendo Kafka, por una literatura menor, ha escrito que: "La lengua minoritaria de la literatura minoritaria implica la desterritorialización de la lengua mayor, la articulación de lo individual en la inmediatez política y un agenciamiento colectivo de enunciación" (30). 


\begin{abstract}
SOMBRAS, DE LOS MUERTOS IMAGINARIOS DE
CONCEPCIÓN, FOTOGRAFIÁNDOSE JUNTO A SUS

VERDUGOS EN LA PLAZA DE LA INDEPENDENCIA,

NOS DEJEN LA IRREALIDAD DE SUS GESTOS,

LA VIDA DE LOS HIJOS DE QUIEN, APAGÁNDOSE

LEJOS DE LA RETÓRICA DEL DOLOR Y LAS

CONFESIONES QUE PUEDA MENTIR LA POESÍA
\end{abstract}

DE LOS TERRITORIOS INFINITOS DE CONCEPCIÓN, DESCOLGÁNDOSE DESDE LOS BALCONES HACIA EL BÍOBÍO, NOS DEJEN NOMBRAR A NUESTROS SERES QUERIDOS, QUE FUERAN LA HIERBA QUE NOS VIO CRECER

NOS DEJEN NOMBRAR A NUESTROS SERES QUERIDOS,

POR LOS MISMOS LUGARES QUE ALGUNA VEZ ELLOS

TOCARON JUNTO A NOSOTROS, QUE ELLOS

RESPIRARON JUNTO A NOSOTROS (47).

"Muertos imaginarios" u "otredades espléndidas" que se fotografían con sus verdugos. Muertos que, además, el sujeto poético también reconoce en la irrealidad de los gestos y en las confesiones mentirosas de la poesía. Es decir, en la otredad irreal del lenguaje de la poesía, en la identidad del otro. Aquello que no es cierto, pero que a la vez también se deja nombrar y respirar de manera colectiva.

Ahora bien, considero que a partir de estos rasgos indiciales y característicos de una literatura menor es igualmente posible configurar una idea de "lectura menor"; esto es: un tipo de lectura que surge desde las condiciones revolucionarias en relación a probables lecturas mayores, en cuanto lecturas críticas dominantes y/o determinadas por el prestigio histórico de la autoridad y el saber. Es por ello que, desde el entendimiento de la lectura como un ejercicio de desterritorialización que afecta al idioma, en tanto "desterritorialización de la lectura" para la manifestación de la otredad, creo que también es posible inferir que toda lectura no solo es un ejercicio político, sino que igualmente adquiere un particular valor colectivo. Una lectura menor, desde tal perspectiva, es entonces aquel tipo de lectura que posiblemente se enfrenta o discute con otras lecturas políticas y colectivamente dominantes para dialogar de manera crítica. Porque mientras la escritura es un ejercicio indiscutiblemente activo, la lectura solamente logra su actividad en virtud de los textos que lee y relaciona, a la vez que reacciona críticamente a los resultados generados por lecturas precedentes. Es decir, una lectura cuya posibilidad de sentido opera en reacción a una actividad lectora y crítica anterior. Una lectura menor que además puede devenir en lectura activa cuando se propone leer y traficar de otro modo los textos que revisa. Una lectura que incluso sea capaz de hacer devenir en lengua extranjera a la propia lengua poética de 
las obras revisadas. Una lectura que no diagnostica enfermedades sino que acontece abogando por la imaginación constante de una nueva salud, en tanto manifestación por una otredad vital. No la lectura utópica, sino la heterotopía del espacio lector.

\section{Consideraciones para una poética traficante}

Desde Aristóteles en adelante, comúnmente se ha dado razón a una definición de poética en función de un conjunto de determinados atributos formales para la configuración de una obra literaria específica. No obstante, un singular contrapunto a la noción aristotélica fue presentado por el teórico búlgaro Tzvetan Todorov, quien en un ensayo titulado Poética utiliza una cita del poeta francés Paul Valery ${ }^{3}$ para precisar con la palabra poética "el nombre de todo aquello que se relaciona con la creación o con la composición de las obras de las cuales el lenguaje es al mismo tiempo la sustancia y el medio, y no el sentido restringido de colección de reglas o de preceptos relativos a la poesía" (19). Por tal motivo, desde la perspectiva de Todorov, es posible afirmar que el entendimiento de la poética ya no corresponde a una descripción de las virtudes retóricas sobre determinados tipos y ejemplos de discursos literarios, sino a la configuración de lo textual-literario en tanto discurso crítico vinculado a una específica capacidad de relación (15) ${ }^{4}$. Es decir, lo poético comprende a aquellos textos que comportan su autosuficiencia en virtud de su modo de relación con estructuras o saberes abstractos, diversos e inestables. Por ello, el estudio de la poética implicaría, más que una descripción formal y/o configuración de los elementos formales para la expresión literaria, una figuración posible al interior de las reflexiones anteriormente ensayadas respecto de una obra poética en particular. En efecto, en el ejercicio de reconocer al lenguaje como sustancia y medio y como mecanismo para abordar la poética específica de una obra determinada, ocurre que tal reconocimiento se convierte a la vez en una nueva proposición. La proposición de una poética posible en que lo poético propiamente tal acontece desde una lectura menor en tanto discurso crítico y relación. Un acontecimiento de salud y una posibilidad de vida. De ahí que Todorov igualmente señale que el objeto de la poética no es solamente la obra literaria misma en tanto manifestación de un discurso particular, sino sobre todo aquello que una obra cualquiera puede ser capaz de interrogar, conectar, provocar, relacionar o hacer funcionar como proyecciones en el pensamiento particular de un lector. En

3 En efecto, las líneas citadas por Todorov corresponden al texto de Paul Valery "De l’enseignement de la poétique au Collège de France" (Todorov 20).

4 Cabe señalar que para Todorov la poética, en tanto estudio, puede ser abordada a partir de dos actitudes o posiciones específicas. Ya sea el estudio del texto literario mismo como objeto autosuficiente o bien el estudio de cada texto en particular pero considerándolo como manifestación de una estructura abstracta. Además, es necesario indicar que para Todorov tales posiciones no son incompatibles, e incluso pueden complementarse de manera recíproca (16-7). 
este marco, la lectura es el intento por la figuración de una poética o una literatura posible, la posibilidad de una literatura en el acontecimiento traficante del lector ${ }^{5}$ (19).

Ahora bien, a propósito de la poética contemporánea, el filósofo francés Jean-Luc Nancy sostiene que la noción de poética no necesariamente equivale a un entendimiento del sentido de las cosas, sino que más bien corresponde a una forma de "hacer poesía" en tanto posibilidad de acceso constante para la elaboración de un sentido cualquiera. Sentido que incluso puede ser constantemente aplazado y/o desplazado de las cosas, de manera tal que el sentido o la posibilidad de sentido de la poesía es siempre una posibilidad de acceso a un sentido por hacer o imaginar (156). Un sentido que acontece en el devenir de las palabras de lo escrito. Algo por leer. Una poética del acontecimiento que vendrá. En Mil mesetas, Deleuze y Guattari también señalan que nunca hay que preguntar qué quiere decir un libro o cuál es su significado profundo, sino cuáles son las posibilidades de operación de los sentidos de un libro cualquiera, con qué funciona, con qué se conecta, si hace pasar o no intensidades, qué provoca, en qué multiplicidades se introduce y metamorfosea (10), pues el discurso poético, siendo cifra de la imaginación del ser humano por medio del lenguaje, es también el resultado constante de una investigación emocional, intelectual, crítica y singular 6 . Por su parte, el teórico de las artes visuales Nicolás Bourriaud ha señalado en Estética relacional que las obras de arte contemporáneo ya no tienen como meta ni la reproducción mimética de la realidad, ni la creación de realidades simbólicas, imaginarias o utópicas, sino la constitución de modos de existencia o modelos de acción y vida dentro de lo real ya existente. Así, según Bourriaud, la poética en el arte relacional es aquella que toma como horizonte teórico la esfera de las interacciones y su contexto social por sobre la afirmación de un tradicional espacio simbólico, autónomo y privado. Situación que evidencia un "cambio radical" de los objetivos estéticos, culturales, políticos y económicos puestos en juego por el arte de la contemporaneidad (13). En un sentido similar, el filósofo Jacques Rancière precisa que la estética relacional es aquella que "rechaza las pretensiones a la autosuficiencia del arte como si fueran sueños de transformación de la vida por el arte, pero reafirma, sin embargo, una idea esencial: el arte consiste en construir espacios y relaciones para reconfigurar material y simbólicamente el espacio común" (17), de manera tal que la recepción de lo artístico comporta un desplazamiento de la percepción para una reconfiguración de lo simbólico.

5 El estudio de los textos literarios, en tanto configuración de/para una poética, ha de ser entendido, siguiendo a Todorov, sobre la base de las capacidades que tiene cada texto literario en particular para interrogar e interrogarse de acuerdo a las propiedades que manifiesta el discurso literario propiamente tal, y no en función de una mera descripción sistemática respecto de los aspectos constitutivos de un texto. De este modo, una obra literaria puede ser también examinada como aquella que permite cuestionar críticamente su autonomía de expresión y sus posibilidades de tráfico. Aquellas escrituras que horadando el lenguaje se ubican en los intersticios de la subjetividad y de la imaginación, en los agujeros de la salud.

6 Según Willy Thayer, el acontecimiento de la lectura en tanto pensamiento poético del lector sobre una obra dada acontece como una manifestación de la singularidad, esto es: "en la intriga relacional de las materias, siendo su forma indeciblemente su contenido, y viceversa, coincidiendo con su cosa que siempre es otra cosa [...] un devenir sin eslabones que sarpulle, erosiona, vacila, hace pliegues" (29). 
En consecuencia, a partir de autores como Todorov, Nancy, Deleuze, Guattari, Bourriaud y Ranciére, he querido reconfigurar el pensamiento sobre la poética contemporánea, considerando sus posibilidades y desplazamientos para imaginar una poética menor en tanto experiencia de la alteridad lectora que deviene relacional y traficante. Una poética de las experiencias e intensidades para una nueva escritura del sujeto lector?. Una "inconmensurable extensión de humo, / de pura imaginación" (Harris, Cipango 150) o "un suceso cotidiano para reconocer la vida" (Miquea, Que nos queremos 49). Así, la escritura es el resultado del encuentro, desencuentro y/o reencuentro del lenguaje mismo en tráfico con los abandonados fragmentos de la fábula de un discurso amoroso. "La fábula [que] sólo podrá ser escrita después / de habernos reunido en la espesura" (70). Pues como efectivamente precisa el poeta:

Puedo fabular y decir que vivo. Puedo

haber existido toda la vida entre los libros

y decir que voy entre los hombres. Tú

que me conoces podrás leer mi nostalgia

o la distancia entre el primer poema

y el alma que aún no encuentro. Tú

eres el término que hace la totalidad.

La abstracción donde se cruzan

todas nuestras señales (Miquea, Libro de Atanasio 35).

Por último, en cuanto a una incipiente idea de "poética traficante", enunciada a partir de la conjunción entre lectura menor, acontecimiento de salud y/o manifestación de la otredad de la poesía por el devenir de una estética relacional, considero pertinente señalar un cierto tipo de paralelismo inicial respecto del alfabeto y la moneda, puesto que, como también indica Roland Barthes, en tal paralelismo hay una profunda relación de la letra con el bien de la comunicación, y de la comunicación con el bien del objeto de cambio (113), "que cambia monedas de oro por poesía" (Miquea, Libro de Atanasio 57). De tal forma que las palabras y las monedas conforman una racionalidad

7 En Por una teoría de la lectura Roland Barthes señala que el fenómeno de la lectura, en tanto producción de escritura surgida a partir de una lectura anterior, puede ser comprendido desde la perspectiva de "lecturas muertas" y "lecturas vivas". Las primeras son aquellas que están sujetas a estereotipos, determinismos, repeticiones mentales y consignas que además corresponden al tipo común de lecturas que deviene en ejercicio de la escritura periodística sobre la literatura; es decir, lecturas muertas que se consolidan en escrituras infértiles. Mientras que las "lecturas vivas" son aquellas que producen una especie de texto interior, semejante a una escritura amorosa y virtual del lector. En este tipo de lecturas vivas, el sujeto lector cree amorosa y emocionalmente en lo que lee al tiempo que conoce y reconoce aquello que Barthes denomina "trampa" o irrealidad del lenguaje poético, pues la lectura viva es una especie de lectura escindida que implica "la escisión del sujeto de la que hablaba Freud" (84). Escisión fundada en una lógica muy distinta de la del cogito; "si recordamos que para Freud la escisión del yo se liga fatalmente a las diferentes formas de la perversión, tendremos que aceptar que la lectura viva es una actividad perversa, y que la lectura es siempre inmoral" (85). Por ello, es sumamente necesario reconocer ahora, junto a Roland Barthes, que el ejercicio menor de la lectura viva se traduce en un acto de la imaginación perversa de la identidad del otro que lee, por ejemplo, a partir de "los signos contagiados de amor [que] se confundieron con los / signos contagiados de violencia" (Harris, Cipango 35), o bien: "El código de lo imprevisto que permite que / las aguas del Biobío sean otras cada día” (Miquea, Que nos queremos 11). 
de intercambio y comunicación, son el resultado de una sintaxis de los encuentros. El dinero, que en sí mismo no es nada, puede convertirse en cualquier cosa, y por su lado los componentes vacíos de las palabras se unen y llenan de significados "por los laberintos del deseo" (Harris, Cipango 91), convirtiendo el deseo en signo. Por ello, en De la gramatología, Jacques Derrida señala que el alfabeto es comercial y, como tal, solo puede ser concebido dentro un momento monetario de racionalidad económica. Una racionalización de la nada a la cosa y de la palabra al sentido; del dinero y del lenguaje al signo (378).

Sin embargo, una racionalidad que es impuesta por el dinero solo es una racionalidad que condiciona las cosas, la vida y el lenguaje en tanto sincronización absoluta de la circulación ilimitada del dinero mismo (Hopenhayn 38); aquello que precisamente se desvanece ante la irracionalidad de la poesía. Palabra que trafica sus sentidos en acontecimientos de otredad. Contradicción de toda racionalidad lingüística y económica posible. Devenir relacional del desplazamiento de la lectura minoritaria a la manifestación de una poética traficante: "quizá sólo por distraerme / o por imaginar que tras cada palabra / siempre hay un pedazo de la vida / de alguien" (Miquea, Libro de Atanasio 118). Un acontecimiento de vitalidad.

\section{Referencias}

Barthes, Roland. "Por una teoría de la lectura". Variaciones sobre la escritura. Barcelona: Paidós, 2002. 83-85. Impreso.

Bourriaud, Nicolás. Estética relacional. Buenos Aires: Adriana Hidalgo, 2008. Impreso. Deleuze, Gilles. Crítica y clínica. Barcelona: Anagrama, 2009. Impreso.

Deleuze, Gilles y Félix Guattari. Mil Mesetas. Valencia: Pre-Textos, 2008. Impreso.

Derrida, Jacques. De la gramatología. México: Siglo xxi, 2005. Impreso.

Faúndez, Edson. La oscura casa encantada: La poesía de César Vallejo y Oliverio Girondo. Concepción: Universidad de Concepción, 2010. Impreso.

Foucault, Michel. De lenguaje y literatura. Barcelona: Paidós, 1996. Impreso.

Guattari, Félix. "El nuevo paradigma estético". Caosmosis. Buenos Aires: Manantial, 1996. 121-144. Impreso.

Harris, Tomás. Cipango. Santiago: Fondo de Cultura Económica, 1996. Impreso.

Hopenhayn, Martín. "El dinero y nosotros en el estallido de la burbuja financiera". Cuaderno 63 (2009): 38-41. Impreso.

Lipovetsky, Gilles. La era del vacío. Barcelona: Anagrama, 2003. Impreso.

Miquea, Nicolás. Que nos queremos tanto. Valparaíso: Gamelianos, 1993. Impreso.

---. Fermosa Fiera. Valparaíso: Poesía de la Quinta, 1999. Impreso.

---. Libro de Atanasio Beley. Concepción: Cosmigonon, 2004. Impreso.

Nancy, Jean-Luc. "Hacer la poesía”. Baldebec 3.5 (2013): 155-163. Impreso. 
Rancière, Jacques. Sobre políticas estéticas. Barcelona: Universidad Autónoma de Barcelona, 2005. Impreso.

Rodríguez Fernández, Mario. “La galaxia poética latinoamericana”. Trilce 9 (2002): 24-38. Impreso.

Thayer, Willy. Tecnologías de la crítica: entre Walter Benjamin y Gilles Deleuze. Santiago: Metales pesados, 2010. Impreso.

Todorov, Tzvetan. Poética. Buenos Aires: Losada, 1975. Impreso.

Recibido: 22 diciembre 2014 Aceptado: 16 julio 2015 